\title{
The spine in sport and veteran military parachutists
}

\author{
C. F. MURRAY-LESLIE, D. J. LINTOTT, AND V. WRIGHT
}

From the Rheumatism Research Unit, University of Leeds, and Department of Diagnostic Radiology, Generaे Infirmary at Leeds

SUMMARY Spinal injuries and symptoms were studied in 109 ex-military parachutists and 112 spote (free fall) parachutists by means of postal questionnaires. 46 ex-military parachutists aged 50 year. or over had a radiological examination of the lumbar spine and 58 sport parachutists had a radiog logical examination of the cervical spine as part of the survey. A history of back pain was significantly $(\mathbf{P}<0.01)$ associated with body weight in sport parachutists but not with the number of descents $\alpha_{0}$ with the subject's age. In the older ex-military group neither age, weight, nor the number of descents was significantly associated with backache.

Of those ex-military parachutists $x$-rayed, $10(21.7 \%)$ were found to have vertebral body fractures (most frequently at D12), and 8 of these were unaware of these lesions. Vertebral fractures caused no disability and did not permanently curtail parachuting activities in either the sport or ex-militarif? group.

Of the ex-military parachutists $x$-rayed, $84.7 \%$ had lumbar disc degeneration of all grades of severity, $17 \cdot 4 \%$ had moderate changes, and $10.8 \%$ had severe changes. The frequency of moderate and severe disc degeneration was significantly related to age but not to body weight or to the number of descents. Spondylolysis was found in 2 subjects $(4.3 \%)$ and spondylolisthesis unassoc를 ated with spondylolysis in $4(8.7 \%)$. Spondylolisthesis was always associated with a history of back pain.

A low prevalence of radiological cervical intervertebral disc degeneration of all grades of severit $\vec{b}$ of $8.7 \%$ was found among the free fall parachutists (mean age 33 years). 2 cases of cervical vertebra body fracture were seen, one related to a parachute landing injury and the other to a parachute opening injury.

This study does not implicate parachuting as a cause of intervertebral disc degeneration, eithe cervical or lumbar, nor as a cause of spondylolysis or spondylolisthesis. Serious long-term disability from pain appears to be uncommon among parachutists despite the frequency of the spinal trauma they sustain.

Parachuting is well known to cause injury to the spinal column, most commonly vertebral body fractures unassociated with spinal cord or nerve root damage (Essex-Lopresti, 1946; Ciccone and Richman, 1948; Neel, 1951; Kirby, 1974). The distribution of these is characteristic with maximal frequency occurring at or around the first lumbar vertebra, and with $30 \%$ of cases having more than the vertebra involved (Neel, 1951; Kirby, 1974). The fractures are typically of the wedge compression type described by Holdsworth (1970), and are usually caused by

Accepted for publication November 26, 1976

Correspondence to Dr. C. F. Murray-Leslie, Dept. of Rheumatology and Rehabilitation, Derbyshire Royal Infirmary, London Road, Derby DE1 $2 Q Y$. landing heavily on the buttocks, in the course of being blown backwards (Ciccone and Richman, 1948; Neel, 1951; Kirby, 1974). The descent rate and hence the vertical component of the eventual landing force under a military parachute will depend principally upon the weight of the man, and for $\frac{a}{2}$ fully equipped soldier weighing $113 \mathrm{~kg}$ will be in the region of $5.4 \mathrm{~m} / \mathrm{s}$ (B. Tansley, personal communicac tion, 1974). Sophisticated modern sport parachute generally have lower descent rates than conventionait hemispherical canopies, but if mishandled ca produce very high descent rates (E. Edmonds personal communication, 1975). The peak decelera tion $g$ forces on the spine in a head-toe direction during a parachute landing have been shown to 
range between $3 \cdot 2$ and $17 \cdot 0$ with a mean of 5.8 for several different types of parachute (Reid et al., 1971).

During the opening of a parachute the spine is subjected to deceleration forces; in the case of a military aircraft slipstream deployment the peak opening forces are around $4.0 \mathrm{~g}$ (Neel, 1951). This is well within the human spinal tolerance limit of $20 \mathrm{~g}$ (Ruff, 1945; Laurell and Nachemson, 1963). In free-fall parachute openings where the falling velocity of the parachutist is frequently of the order of 55.4 to $61.5 \mathrm{~m} / \mathrm{s}$, peak opening shock forces are higher than in military openings and inhibiting devices have to be fitted to slow the opening sequence of the parachute (Reid et al., 1971; E. Edmonds, personal communication, 1975). Peak head-to-toe $g$ forces of between 3.0 and $15 \mathrm{~m} / \mathrm{s}$ with a mean of $7 \cdot 8$ have been reported during a series of terminal velocity openings on different free-fall parachutes with inhibiting devices fitted (Reid et al., 1971).

No systematic study of the long-term effects of parachuting on the spine has been made. This study investigates the prevalence of lumbar intervertebral disc degeneration, vertebral body fracture, spondylolysis (Wiltse, 1962; Newman, 1963; Turner and Bianco, 1971; Wiltse et al., 1975), and spondylolisthesis (Newman, 1963; Wiltse, 1962; Rosenberg, 1975 ) in veteran military parachutists and the effects of parachute opening forces on the cervical spine in sport parachutists.

\section{Subjects and methods}

Medical and parachuting information was obtained from 112 experienced and active (free fall) parachutists and 109 ex-military parachutists by postal questionnaire as described previously (Murray-Leslie et al., 1977).

In addition to the radiography described previously (Murray-Leslie et al., 1977) the ex-military parachutists who were aged 50 or more and who were agreeable, had lateral and left and right oblique

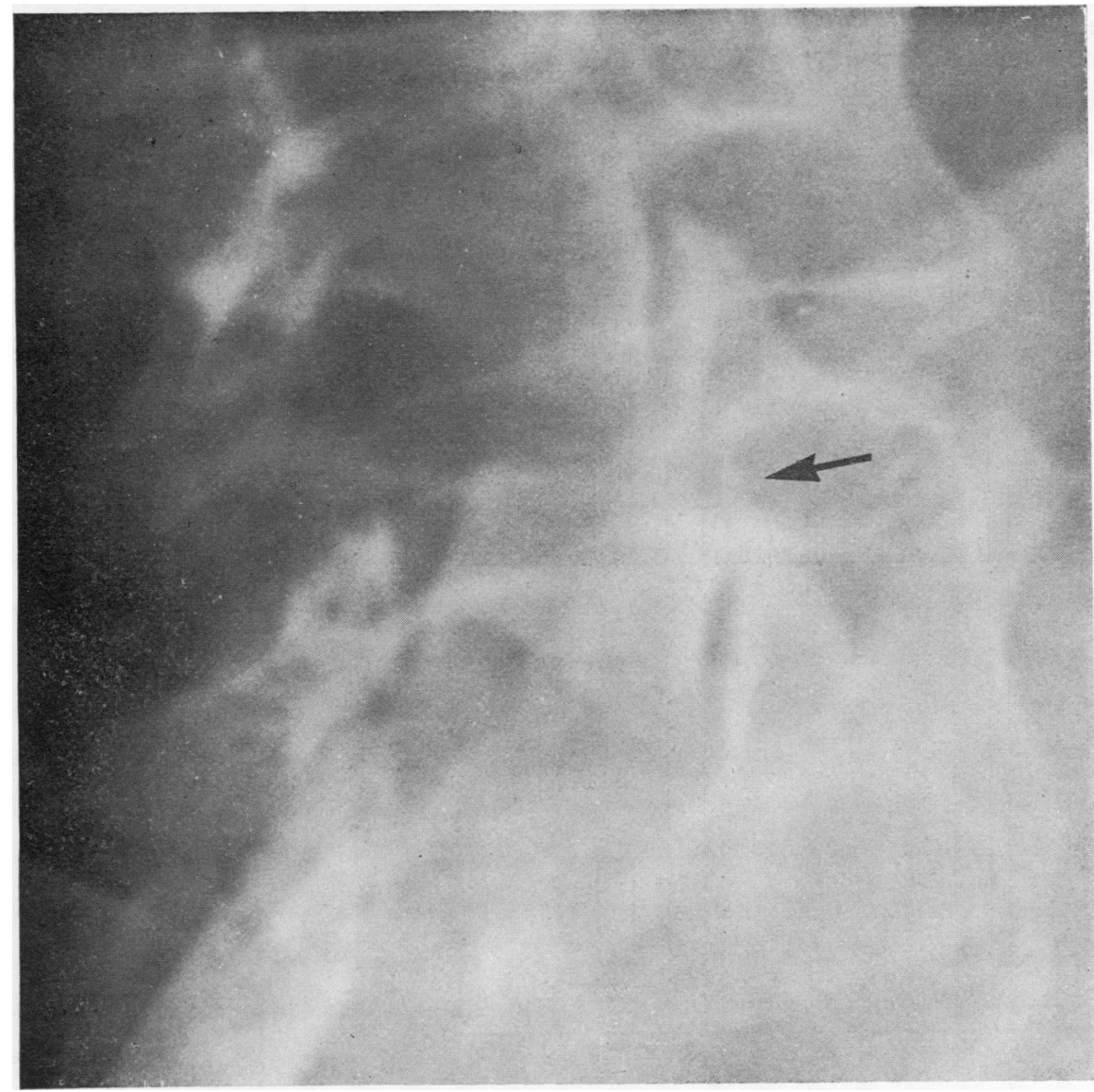

Fig. 1 Appearance of a pars interarticularis simulating spondylolysis. 
radiographs of the lumbar spine. Volunteers from among the free-fall parachutists had a lateral radiograph of the cervical spine.

\section{RADIOLOGICAL ASSESSMENTS}

The lateral lumbar spine radiographs were assessed for intervertebral disc degeneration by one of us (D.J.L.), in randomized sequence and in ignorance of the subjects' identities, medical or parachuting history. In obtaining an overall grade for each disc space, narrowing and osteophytosis were assessed separately using a 5 point grading scale $(0=$ normal, $1=$ doubtful, $2=$ mild, $3=$ moderate, $4=$ severe) and the highest grade for either feature was taken. Spondylolisthesis was recorded, and the level, degree, and direction of slip noted. Vertebral body fractures were recorded. The partes interarticulares seen in the right and left oblique radiographs of the lumbar spine were examined for spondylolysis and this feature recorded as present or absent at each level. Only clear and complete breaks in the bony continuity of the partes were taken as constituting spondylolysis. Sclerosis and apparent or incomplete areas of radiolucency such as shown in Fig. 1 were not regarded as adequate evidence of spondylolysis.
Marked degenerative changes in the apophysea $\mathrm{P}$. joints were also recorded if present and any association with spondylolisthesis noted.

The cervical spine radiographs taken in the free fall parachutists were also examined in randomize

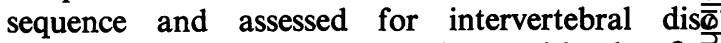
degeneration by comparing them with the five grades of severity illustrated in the Standard Atlase of Radiographs of Arthritis (Jeffrey et al., 1963). Any vertebral body fractures presen $\neq$ were recorded.

\section{Results}

COMPOSITION OF GROUPS STUDIED

The ages and details of the parachuting experience of each of the two groups of parachutists studied given in the preceding article describing the effects of parachuting on the knees and ankles (Murray Leslie et al., 1977). The principal differences were that the free-fall parachutists were all parachuting the time of the study, were younger, and as a rule had carried out a greater number of descents over. a shorter period than had their ex-military countery parts.

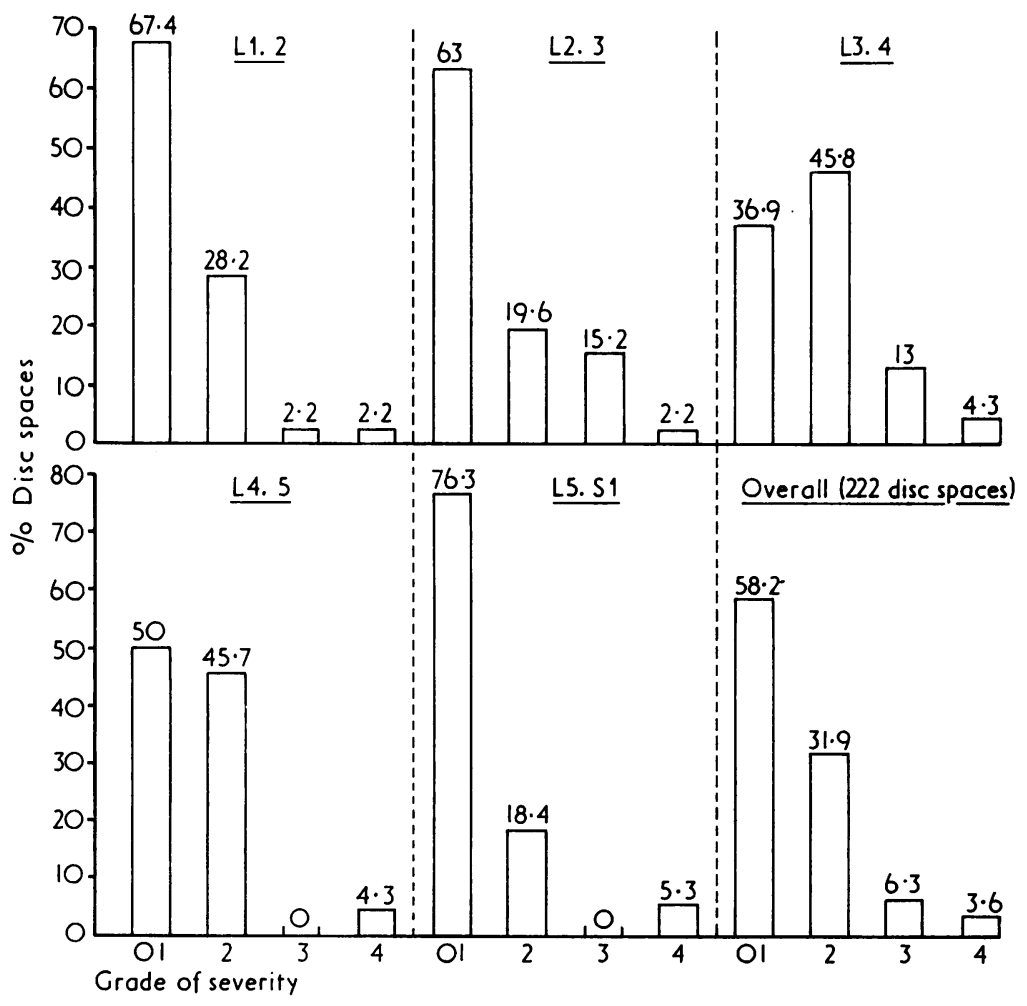

Fig. 2 Prevalence of degeneration of each grade of $D$ severity at each lumbar intervertebral disc level. 
SPINAL INJURIES

The number of subjects reporting either vertebral fractures or soft tissue back injuries, when engaged in parachuting or nonparachuting activities, is given in Table 1.

\section{BACK SYMPTOMS IN SPORT PARACHUTISTS}

Of the sport parachutists (mean age 33 years), 50 $(44.5 \%)$ reported having suffered from backache, either in the past or currently, and $22(19.6 \%)$ had lost time at work through backache. 11 parachutists $(9 \cdot 8 \%)$ complained of persistent or recurrent backache and 2 had had laminectomies. A history of backache was significantly associated with an increased body weight $(t=2.85, P<0.01)$ but not with age or the number of descents carried out. In this highly experienced group all actively engaged in parachuting at the time of the survey, $16 \%$ specified backache as a consequence of an intensive spell of parachuting, as compared with generalized stiffness and aching in $82 \%$ and knee pain in $4 \%$. Minor
Table 1 Spinal ('back') injuries, both fractures and nonfractures reported in questionnaires by 112 sport and 109 ex-military parachutists

\begin{tabular}{|c|c|c|c|c|}
\hline & \multicolumn{2}{|c|}{$\begin{array}{l}\text { Sport parachutists } \\
\text { (112) } \\
\text { no. with back injuries }\end{array}$} & \multicolumn{2}{|c|}{$\begin{array}{l}\text { Ex-military parachutists } \\
(109) \\
\text { no. with back injuries }\end{array}$} \\
\hline & Parachuting & $\begin{array}{l}\text { Non- } \\
\text { parachuting }\end{array}$ & Parachuting & $\begin{array}{l}\text { Non- } \\
\text { parachuting }\end{array}$ \\
\hline $\begin{array}{l}\text { Vertebral } \\
\text { fracture }\end{array}$ & $17(15 \%)$ & 0 & $13(11.9 \%)$ & $2(1.8 \%)$ \\
\hline $\begin{array}{l}\text { Soft tissue } \\
\text { back injuries }\end{array}$ & $19(16.9 \%)$ & $12(10 \cdot 7 \%)$ & $2(1.8 \%)$ & $2(1.8 \%)$ \\
\hline
\end{tabular}

symptoms from parachute opening shocks were frequent, with 59 parachutists $(53 \%)$ remembering at least one unpleasant opening often due to a head down position during parachute deployment and canopy inflation or the use of a parachute without a device to retard the opening sequence. Of those who had symptoms after a parachute deployment, 16 $(14.3 \%)$ had experienced back pain at least once,

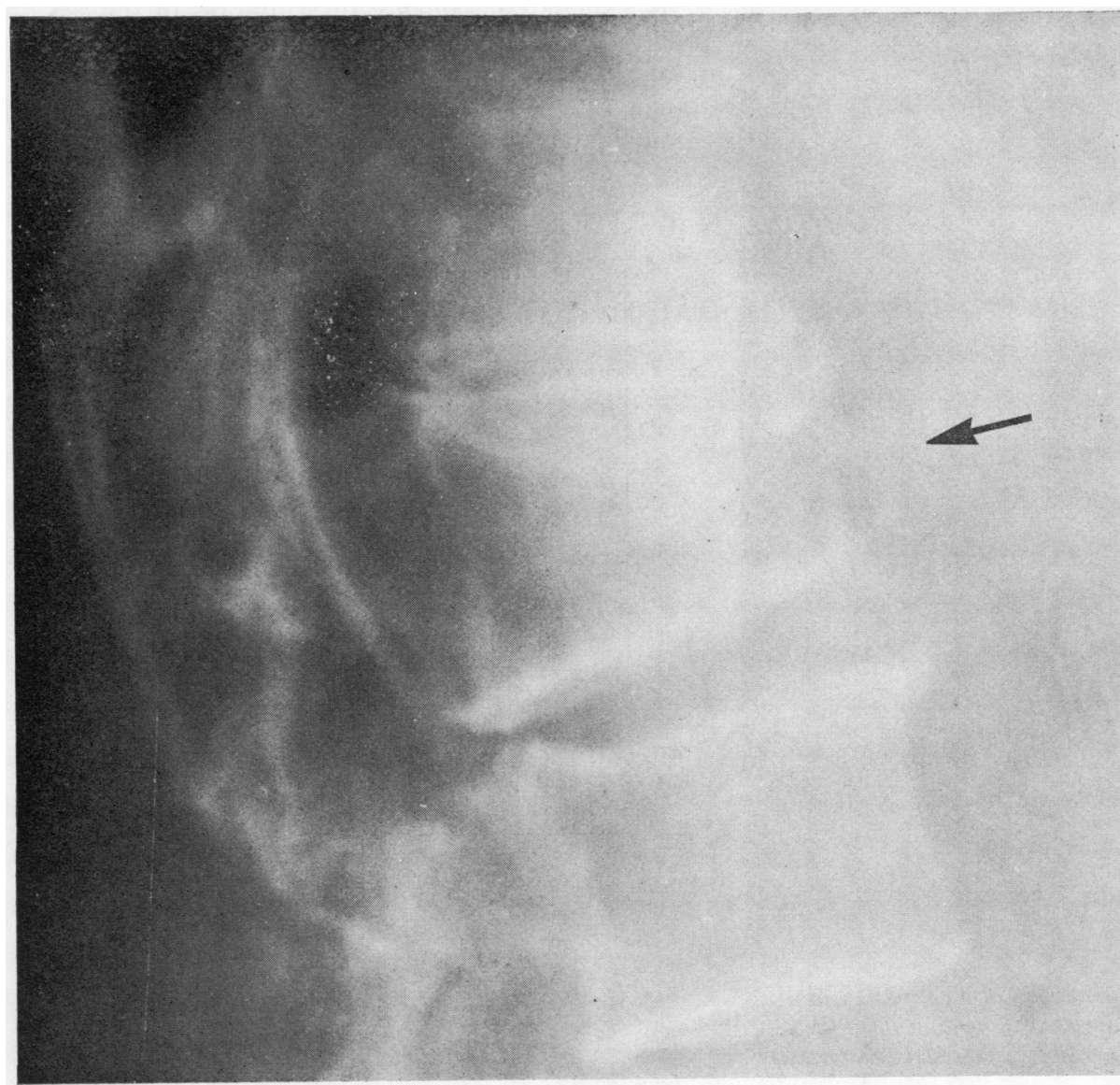

Fig. 3 Vertebral body fracture at $L 2$ in an ex-military parachutist. 
$33(29 \cdot 5 \%)$ neck and shoulder pain, and $20(17 \cdot 8 \%)$ had become transiently dizzy on at least one occasion. 2 subjects reported major incidents after hard parachute openings: one had had a fracture of the 6th cervical vertebra, another had become unconscious for 30 minutes and had developed

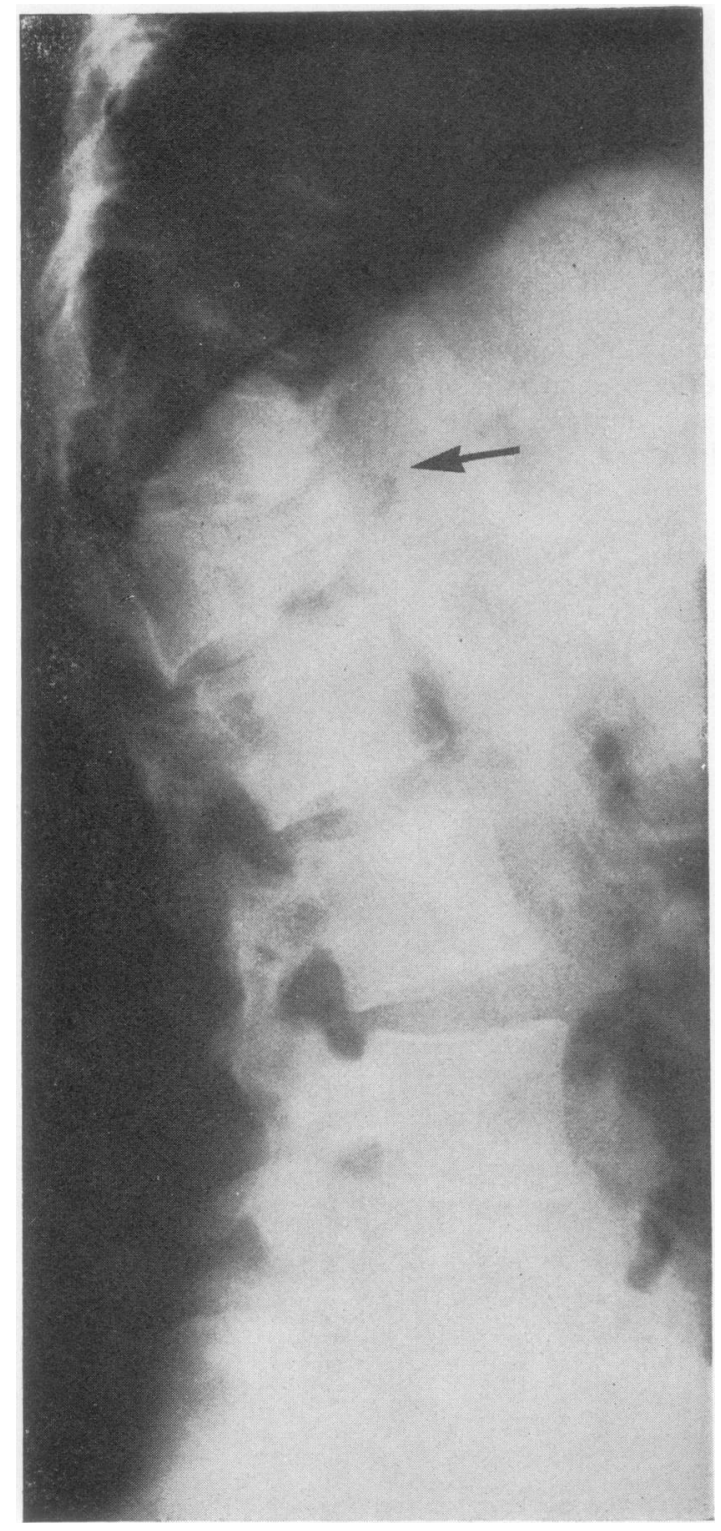

Fig. 4 Vertebral body fractures at T12 and LI in a 32-year-old sport parachutist sustained on this 8th descent. He has subsequently carried out 1000 descents and has no back pain. weakness and mild neurological signs in the legg after an opening.

BACK SYMPTOMS IN EX-MILITARY PARACHUTISTS Of this group (mean age $47 \cdot 8$ years), none st parachuting at the time of the survey, $61(56 \%)$ gave a history of past or present backache and $26(23.8 \%$ had lost time from work with backache. 15 pararchutists $(13.4 \%)$ complained of persistent or recurrent backache and one had had a laminectom $f_{i}$ A history of backache was not significantly correlated with either weight, age, or the number of parachuge jumps, but was more frequent $(76.9 \%)$ in those wif severe and moderate disc degeneration in the lumbar spine than in those with normal, doubtful, or mif changes $(39.4 \%)$. The majority of the group coto sidered that parachuting had caused them no harin but of the $18(16.5 \%)$ who felt at the time of the survey that they had symptoms attributable to parachuting, $6(5.5 \%)$ specified backache and neck pain.

Of the 6 parachutists who had stopped parachutiog as a direct consequence of symptoms or injuries, $\vec{b}$ $(1.8 \%)$ had sustained back injuries. Of the remaindery one had leg shortening resulting from a fractured femur, 2 had severe persistent knee symptoms, ared one had a severe ankle fracture.

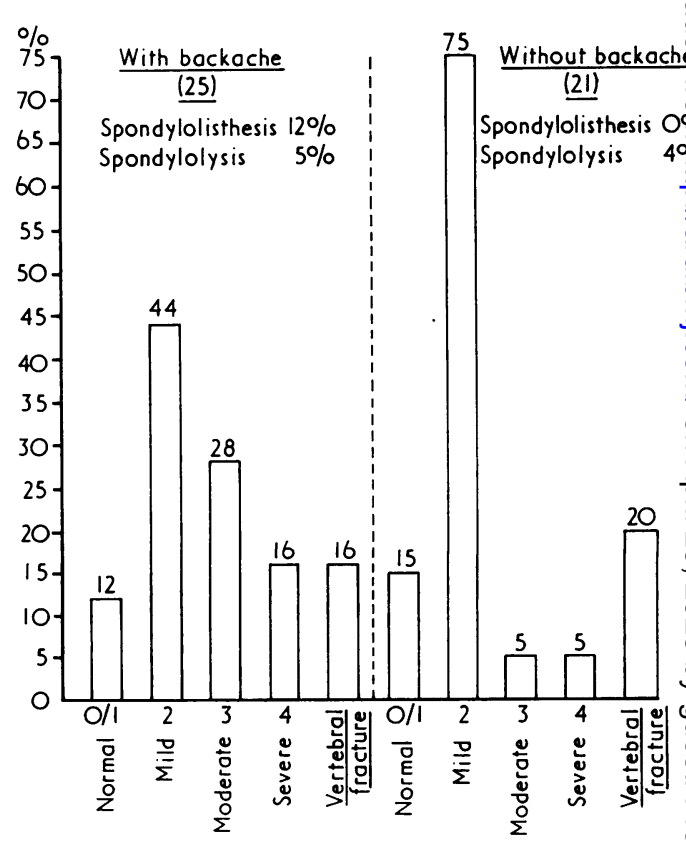

Fig. 5 Distribution of vertebral body fracture, grades disc degeneration, spondylolysis, and spondylolisthesis between those parachutists with and without a history of back pain. 


\section{RADIOLOGY}

Forty-six ex-military parachutists over 50 years of age (mean age 45 years) underwent radiology of the lumbar spine (a completion rate of $73 \%$ ) and 58 sport parachutists (mean age 33 years) had radiology of the cervical spine (a completion rate of $69 \cdot 8 \%$ ).

\section{Lumbar spine in ex-military parachutists}

The overall grading of the intervertebral disc degeneration usually depended on the severity of the osteophytosis seen, and of the 222 disc spaces visualized and graded in the lumbar spine in only four instances was disc space narrowing given a higher grade than osteophytosis and this narrowing was mild (grade 2) in three and moderate (grade 3) in one instance (Fig. 10). The grading of osteophytosis in this study closely resembled the osteophytosis of the composite grades $(0-4)$ shown in the Standard Atlas of Radiographs of Arthritis (Jeffrey et al., 1963).

The prevalence of intervertebral disc degeneration at each vertebral level for each grade of severity is shown in Fig. 2, and the frequency of multiple disc degeneration occurring in the same spine in Table 2. $39(84.8 \%)$ of the spines examined had some degree of disc degeneration (grades 2-4), with $26(56.5 \%)$ having no more than mild (grade 2 ) changes present, $8(17.4 \%)$ no more than moderate (grade 3 ) changes, and $5(10.9 \%)$ severe (grade 4$)$ changes. Parachutists showing at least one disc with moderate (grade 3 ) or

Table 2 Prevalence of multiple intervertebral disc degeneration in the lumbar spines of 46 ex-military pararhutists (mean age 55 years)

\begin{tabular}{lcc}
\hline $\begin{array}{l}\text { No. of discs } \\
\text { involved }\end{array}$ & \multicolumn{2}{l}{ No. of subjects } \\
\cline { 2 - 3 } & Grade 2-4 & Grade 3-4 \\
\hline 1 & $39(84 \cdot 8 \%)$ & $13(28 \cdot 3 \%)$ \\
2 & $28(60 \cdot 8 \%)$ & $7(15 \cdot 2 \%)$ \\
3 & $16(34 \cdot 8 \%)$ & $2(4 \cdot 4 \%)$ \\
4 & $6(13.0 \%)$ & $1(2 \cdot 2 \%)$ \\
5 & $1(2 \cdot 2 \%)$ & 0 \\
\hline
\end{tabular}

See Table 4 for explanation of grades.

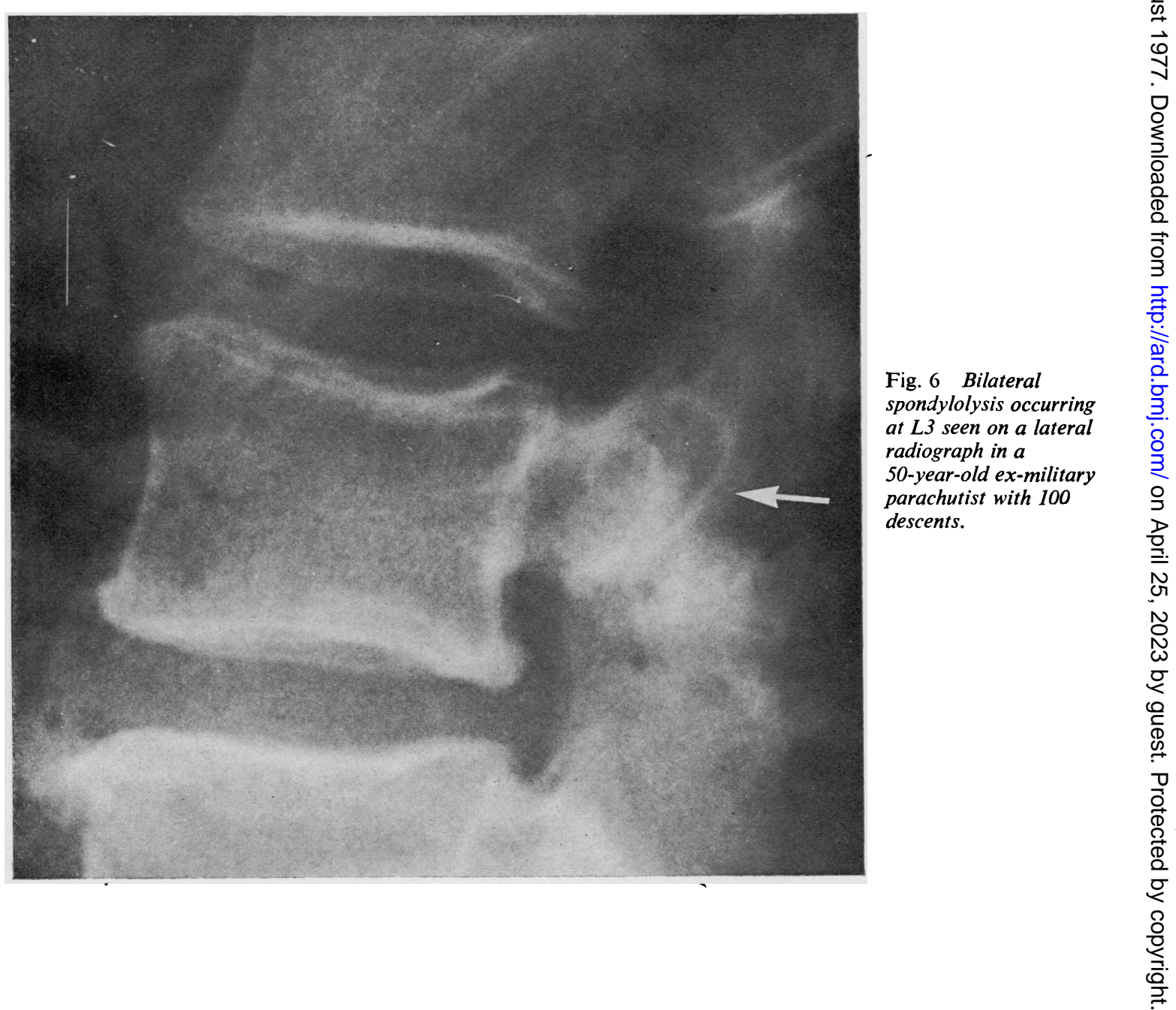


severe (grade 4) changes in their lumbar spines were significantly older than those with normal (grade 0), doubtful (grade 1), or mild changes (grade 2) $(t=3 \cdot 24,0 \cdot 01>P>0.005)$. No significant relationship to body weight or the number of parachute descents made between these groups was found. Subjects with two or more moderate or severely degenerated lumbar discs were also significantly older $(t=3.46,0.02>P>0.01)$, but not heavier or more experienced in terms of descents compared with those with only one moderate or severely degenerated lumbar disc.

Fourteen vertebral body fractures were seen in 10 subjects $(21.7 \%$ ) (Figs. 3,4$)$ and their frequency at each level is given in Table 3.8 subjects had been unaware of the vertebral body fractures and 6 were unable to remember any specific injury which might have accounted for these. The distribution of the fractures in subjects with and without backache is shown in Fig. 5. Four instances of spondylolisthesis with less than a $25 \%$ diameter slip were seen in 4 subjects $(8.7 \%)$ and their distribution in the lumbar spine is shown in Table 3 . In one the spondylolisthesis at L4/5 was associated with marked osteoarthrosis of the apophyseal joints, and in another the slip at L3/L4 was reversed. All the subjects with spondylolisthesis gave a history of backache (Fig. 5).
Table 3 Frequency and site of vertebral body fractureste. spondylolisthesis, and spondylolysis in 46 ex-military parachutists

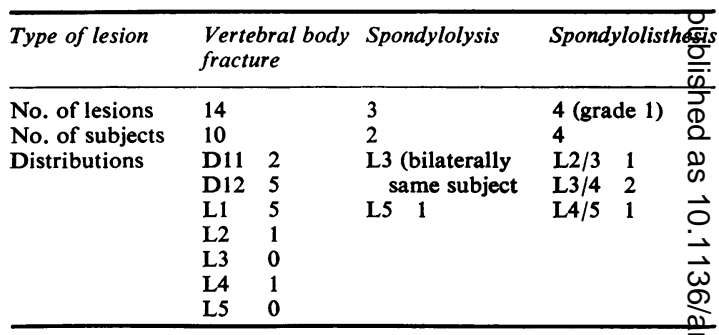

Spondylolysis of the partes interarticulares was found in 2 subjects $(6.5 \%)$, occurring at L5 on the right in one subject, unassociated with back pain or spondylolisthesis, and occurring bilaterally at L3 $\$$ the other subject where it was associated with baek pain but not with spondylolisthesis (Figs. 6 and 7 .

\section{Cervical spine in sport parachutists}

The prevalence of cervical intervertebral disc degeneration is shown in Table 4. Two instances of fracture of the bodies of cervical vertebrae were seen. One at C6 (Fig. 8) was related to a parachu opening shock taken in a head down position, the

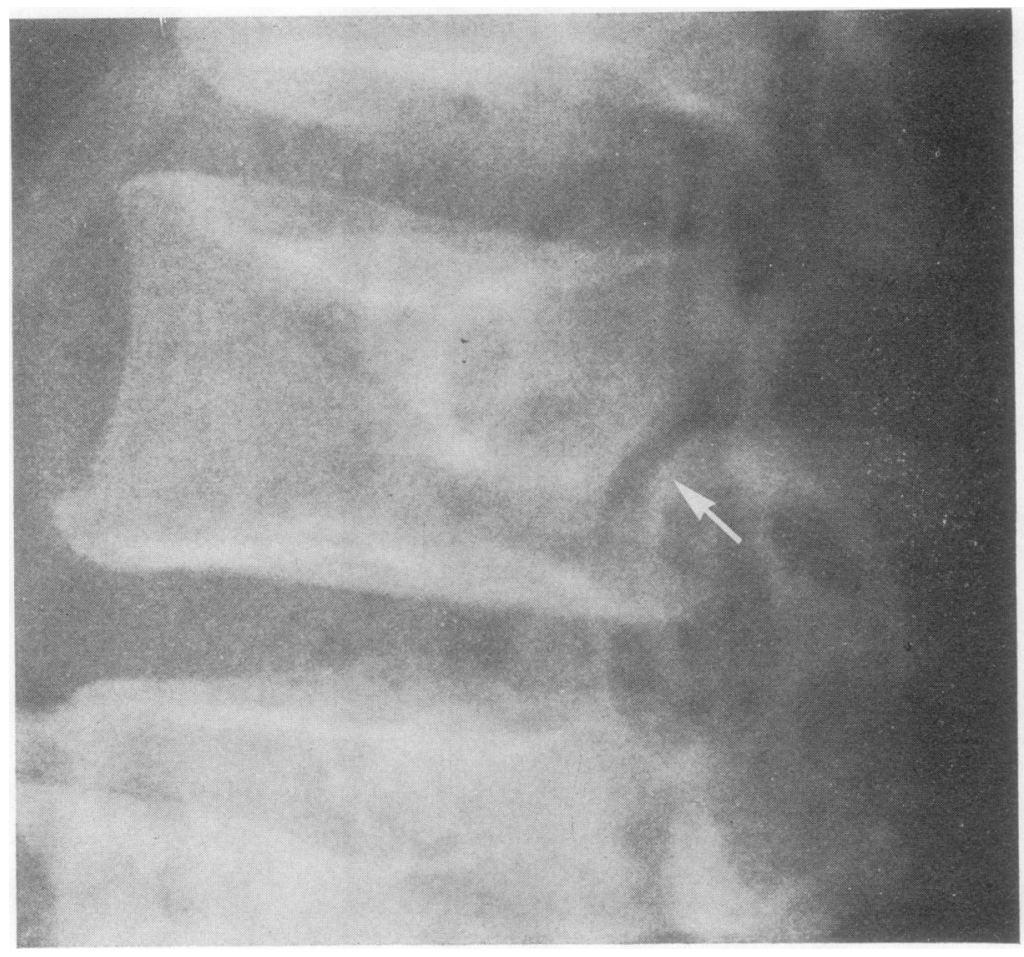

Fig. 7 One of the lesions seen Fig. 6 on a left oblique radiograpes. 
Table 4 Frequency of cervical intervertebral disc degeneration in 58 sport parachutists (mean age 33 years)

\begin{tabular}{|c|c|c|c|c|}
\hline \multirow[b]{2}{*}{ Level } & \multicolumn{4}{|c|}{ Grade of severity (\%) } \\
\hline & $\begin{array}{l}0+1 \\
\text { normal and } \\
\text { doubtful }\end{array}$ & $\begin{array}{l}2 \\
\text { mild }\end{array}$ & $\begin{array}{l}3 \\
\text { moderate }\end{array}$ & $\begin{array}{l}4 \\
\text { severe }\end{array}$ \\
\hline $\mathrm{C} 2 / 3$ & 100 & - & - & - \\
\hline $\mathrm{C} 3 / 4$ & 100 & - & - & - \\
\hline $\mathrm{C} 4 / 5$ & 100 & - & - & - \\
\hline C5/6 & 92.9 & $7 \cdot 1$ & - & - \\
\hline $\mathrm{C} 6 / 7$ & 93 & $5 \cdot 3$ & 1.7 & - \\
\hline
\end{tabular}

other a fracture dislocation at $\mathrm{C} 4$ (Fig. 9) resulted from a flexion injury of the neck on landing in high winds.

\section{Discussion}

The prevalence of vertebral body fractures reported by sport and ex-forces parachutists of 15 and $11.9 \%$ respectively is similar, despite more descents having been made by the former group (mean 788, range 200-2966) compared with the latter (mean 236, range $7-1600$ ). However, the finding that $80 \%$ of the ex-military parachutists were apparently unaware of vertebral fractures discovered by radiology during this survey suggests that either some of these fractures were not initially painful or, more likely, that they either were not $x$-rayed initially or have a short memory for such injuries. In keeping with the last suggestion is the low reported frequency of back injury in both groups $(16.9 \%$ for sport and $1.8 \%$ for ex-military), and the staunch conviction of both groups that parachuting did not or had not caused them any harm apart from limb fractures. Back injuries had in fact only caused 2 men $(1.8 \%)$, both in the ex-military group, to give up parachuting.

Present or previous back pain of all grades of severity was reported with similar frequency by both groups of parachutists, but it is possible that although the free-fall parachutists were younger the opportunities for backache may have been greater owing to their much greater parachuting activityoften 4 to 8 jumps in a day.

Although the method of grading lumbar disc degeneration is a little different from the method used by Lawrence (1969), the overall prevalence of lumbar disc degeneration (grades 2-4) and the prevalence of the severer grades $(3 \& 4)$ seems to be higher in the ex-military parachutists studied than in a sample of men of comparable age from the general population (Table 5).

The prevalence of spondylolysis of the lumbar partes interarticulares in this series, three lesions in 2 subjects $(4 \cdot 3 \%)$ and unassociated with spondylolisthesis, is less than has been reported for the general population (Roche and Rowe, 1952; Baker and McHollick, 1956; King, 1966). However, on the films available it was not possible to make a decision about the presence or absence of spondylolysis at every level in every subject and films were not

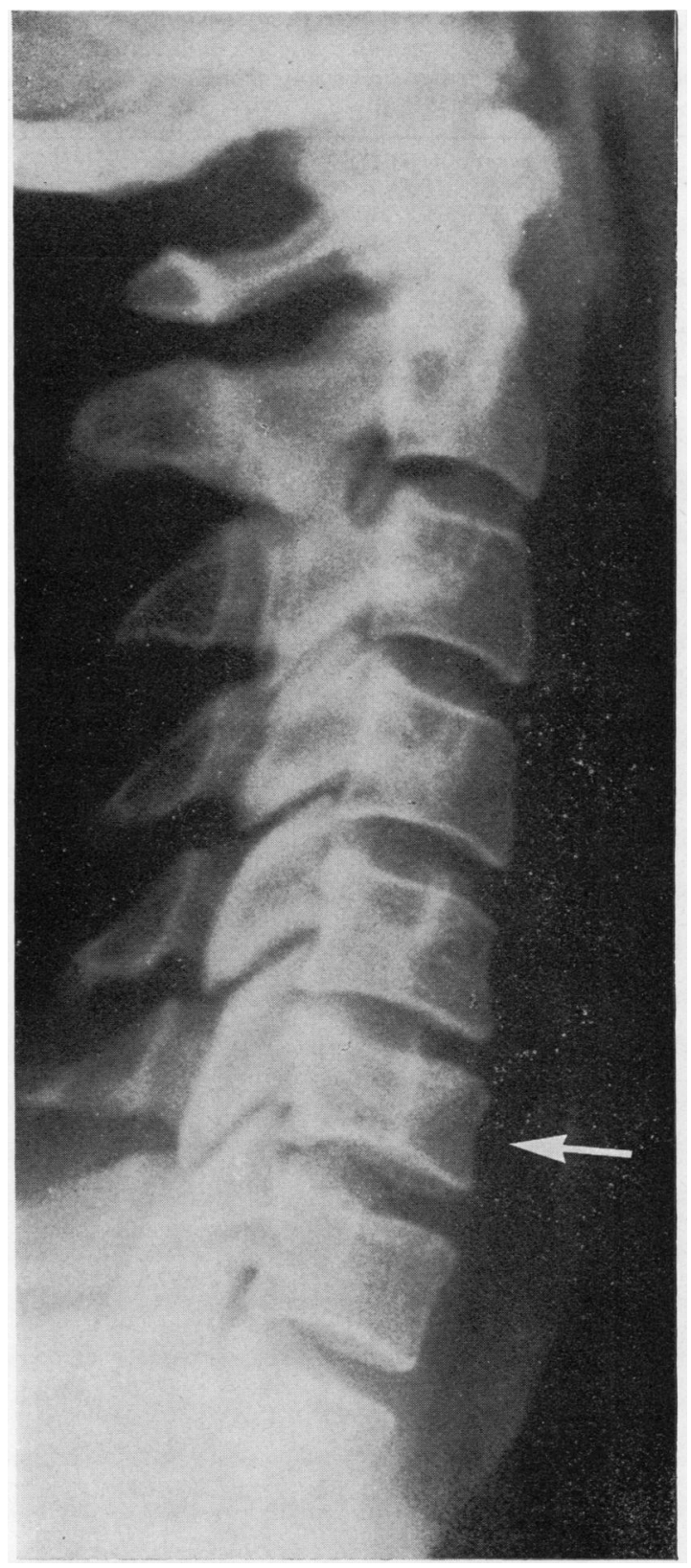

Fig. 8 Fracture of body of C6 in a 37-year-old sport parachutist caused by a parachute opening shock. 
repeated for technical reasons owing to the study involving volunteers. In all, $20 \%$ of the 460 lumbar partes were not sufficiently well-defined for a decision to be made.

Although cervical vertebral body fractures and

Table 5 Comparison of the frequency of lumbar intervertebral disc degeneration in 46 ex-military parachutists with men of similar age from a population survey

\begin{tabular}{lll}
\hline & $\begin{array}{l}\text { Population survey (\%) } \\
\text { (Lawrence, 1969) } \\
154 \text { men (54 to 64 years) }\end{array}$ & $\begin{array}{l}\text { Ex-military parachutists (\%) } \\
46 \text { men (50 to 70 years, mean } \\
55 \cdot 2 \text { years) }\end{array}$ \\
\hline Grade 2 & 59.8 & $56 \cdot 5$ \\
Grade 3 & 16.2 & 17.4 \\
Grade 4 & 3.9 & 10.9 \\
Grades 2-4 & 77.9 & 84.8 \\
\hline
\end{tabular}

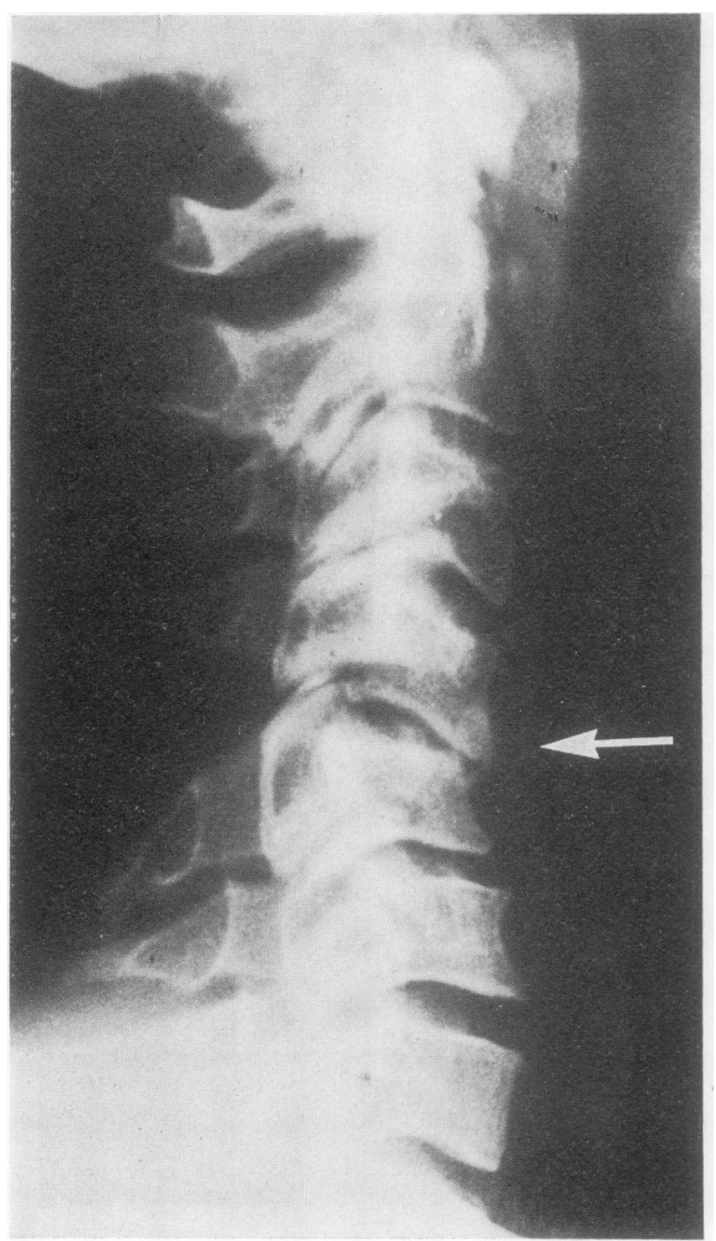

Fig. 9 Fracture/dislocation at C4/5 in a 36-year-old sport parachutist as a result of a backward landing. neurological damage can rarely occur on parachựe deployment, premature degenerative disc disease does not appear to be a feature of free-fall para chuting.

This study has shown a moderately increased prevalence of moderate and severe lumbar intervertebral disc degeneration in the 46 ex-militasy parachutists studied radiologically, which does not seem to be directly related to the number of descents carried out, or the subject's weight, but related more to the subject's age. Severe back pain and long-teram disability were uncommon. They usually did not accompany the more marked lumbar disc degener⿳⺈tion (Fig. 11) and were never associated wigh previous vertebral body fractures (Fig. 4).

We particularly thank the parachutists who to part, but also the radiologists and radiographes, both military and civilian, who organized the radiology; the British Parachute Association; Irvi of Great Britain Ltd.; Wing Commander Turnbull; Squadron Leader D. Reader of R.A. Farnborough, R.A.F. Boscombe Down; and Color M. Hector, Dr. J. T. Patton, Dr. J. C. MacLarnon, Major J. Loveday, Major W. H. Leach, Lt. Cö. I. M. Carmichael, Mr. A. C. Quinlan, Mr. H. \$. Bentley, Miss E. Robbins, Mrs. R. Hopkins, a id Mrs. J. Battersby for their generous help.

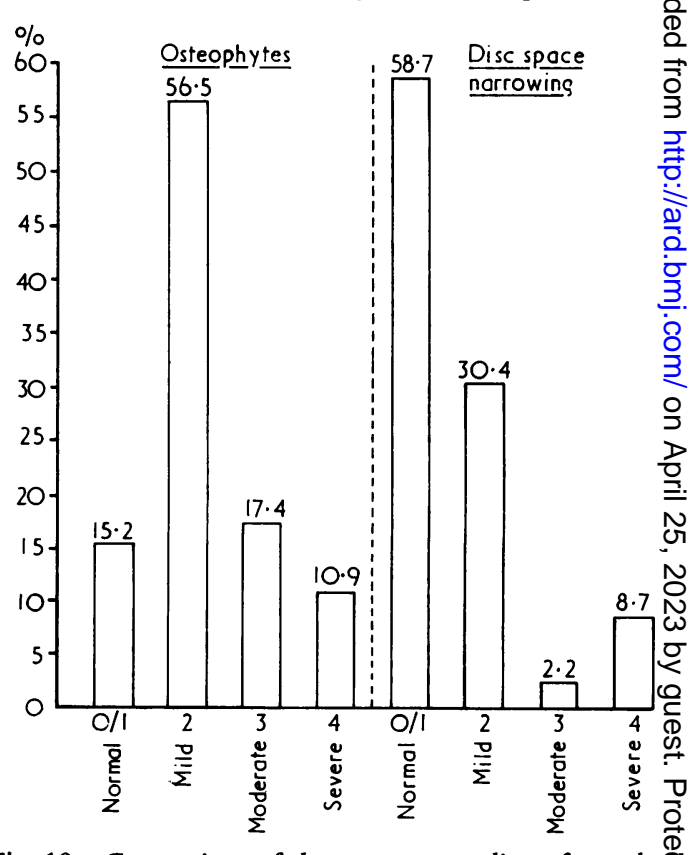

Fig. 10 Comparison of the separate grading of vertebra osteophytes and intervertebral disc space narrowing in the same series of lumbar spine radiographs of 46 ex-military parachutists. 


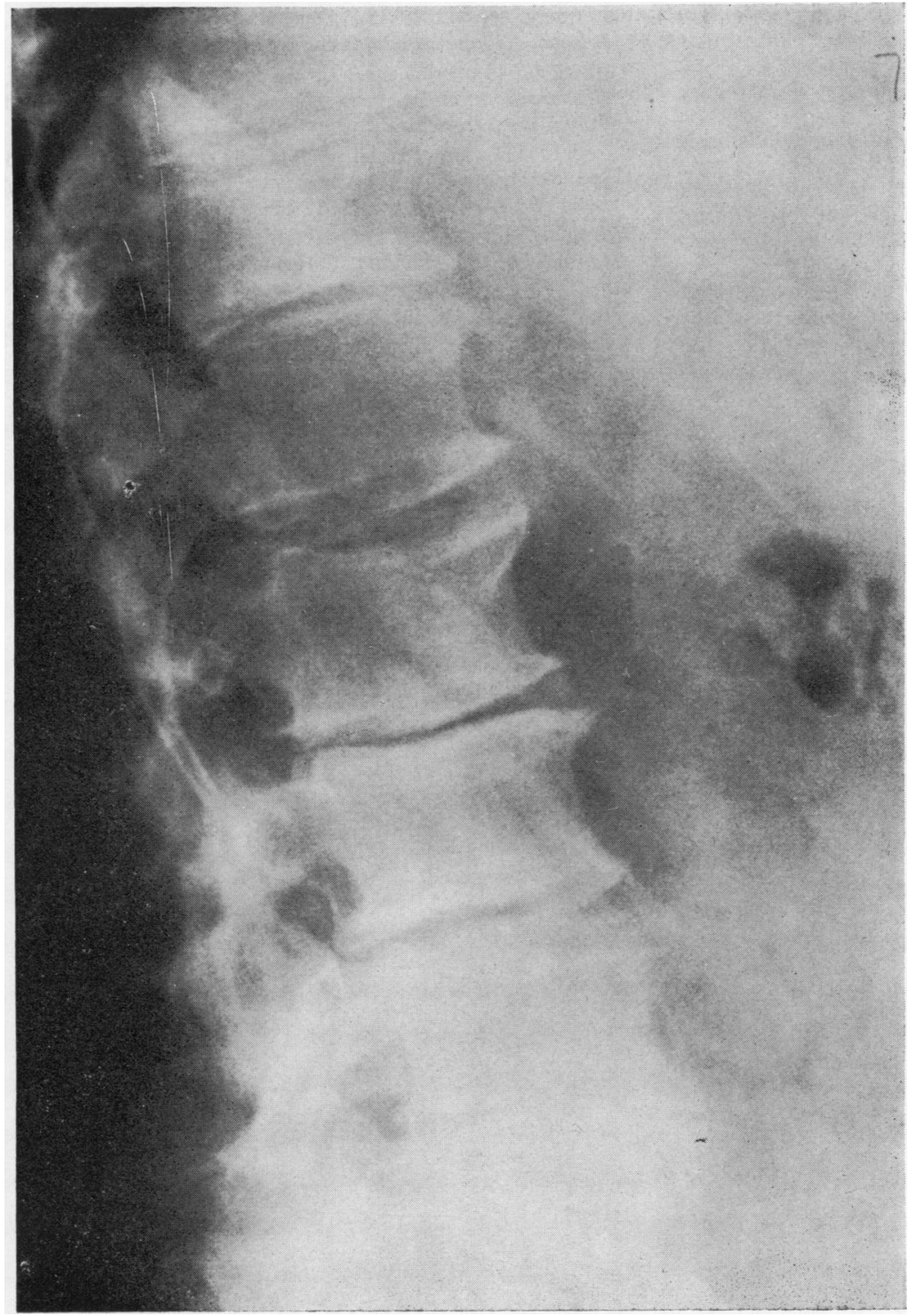

Fig. 11 Severe degenerative changes in the lumbar space of a 60-year-old ex-RAF parachute instructor who made 1200 descents over 18 vears with a body weight of $90 \mathrm{~kg}$, and who does not currently suffer from back pain.

\section{References}

Baker, D., and McHollick, W. (1956). Spondyloschisis and spondylolisthesis in children. Journal of Bone and Joint Surgery, 38A, 933-934.

Ciccone, R., and Richman, R. M. (1948). Mechanism of injury and distribution of 3000 fractures and dislocations caused by parachute jumping. Journal of Bone and Joint Surgery, 30A, 77-97.

Essex-Lopresti, P. (1946). The hazards of parachuting. British Journal of Surgery, 34, 1-13.

Holdsworth, F. (1970). Fractures, dislocations and fracturedislocations of the spine. Journal of Bone and Joint Surgery, 52A. 1534-1551.
Jeffrey, M. R., Kellgren, J. H., and Ball, J. R. (1963). The Epidemiology of Chronic Rheumatism. Vol. II. Atlas of Standard Radiographs of Arthritis. Blackwell, Oxford.

King, A. B. (1966). Experiences with spondylolisthesis. Johns Hopkins Medical Journal, 118, 2-9.

Kirby, N. G. (1974). Parachuting injuries. Proceedings of the Royal Society of Medicine, 67, 17-21.

Laurell, L., and Nachemson, A. (1963). Some factors influencing spinal injuries in seat ejected pilots. Aerospace Medicine, 34, 726-729.

Lawrence, J. S. (1969). Disc degeneration: its frequency and relationship to symptoms. Annals of the Rheumatic Diseases, 28, 121-138. 
Murray-Leslie, C. F., Lintott, D., and Wright, V. (1977). The knees and ankles in sport and veteran military parachutists. Annals of the Rheumatic Diseases, 36, 327-331.

Neel, S. H. (1951). Medical aspects of military parachuting. Military Surgeon, 108, 91-105.

Newman, P. H. (1963). The aetiology of spondylolisthesis. Journal of Bone and Joint Surgery, 45B, 39-59.

Reid, D. H., Doerr, J. E., Doshier, H. D., and Ellerston, D. G. (1971). Acccleration and opening shock forces during free fall parachuting via FM/FM telemetry. Aerospace Medicine, 42, 1207-1212.

Roche, M. B., and Rowe, G. G. (1952). The incidence of separate neural arch and coincident bone variations. Journal of Bone and Joint Surgery, 34A, 491-494.
Rosenberg, N. J. (1975). Degenerative spondylolisthesił Journal of Bone and Joint Surgery, 57A, 467-474.

Ruff, S. (1945). Brief acceleration in less than one second German Aviation Medicine, World War 2, p. 584, United States Government Printing Office, Washington, D.C.

Turner, R. H., and Bianco, A. J. (1971). Spondylolysis and spondylolisthesis in children and teenagers. Journal o Bone and Joint Surgery, 53A, 1298-1306.

Wiltse, L. L. (1962). The aetiology of spondylolisthesi\& Journal of Bone and Joint Surgery, 44A, 539-560.

Wiltse, L. L., Widell, E. H., and Jackson, D. W. (1975) Fatigue fracture: the basic lesion in isthmic spondylolisthesis. Journal of Bone and Joint Surgery, 57A, 17-22. 